\section{Using a Chill Unit/Growing Degree Hour Model to Assess Spring Freeze Risks for 'Redhaven' Peach Trees}

\author{
Joanne Logan ${ }^{1}$, Dennis E. Deyton ${ }^{2}$ and David W. LockWood ${ }^{3}$ \\ Department of Plant and Soil Science, The University of Tennessee, \\ Knoxville, TN 37901-1071
}

Additional index words. phenology, growing degree hours, Prunus persica

\begin{abstract}
Peach [Prunus persica (L.) Batsch] production in Tennessee has declined since 1985 due to the occurrence of freezing temperatures that kill the buds, usually in the spring. Analyses of long-term (1951-89) daily temperature data from four locations in Tennessee were used to evaluate the freeze risks for 'Redhaven' peach tree buds at those sites. A model using daily accumulated chill units and growing degree hours (base 4.4C air temperature) was used to estimate the dates to begin and end chill unit accumulations and the dates of full bloom of 'Redhaven' peach trees for each year in the climatological record. The actual dates of freezes with air temperatures at or below $-2.2 \mathrm{C}$ and the estimated bud developmental stage on the date of each freeze also were determined. The model was tested using peach orchard records and was found to be an improvement over using only freeze data. The model indicated that Spring Hill had the highest risk for peach production and Jackson the lowest. Recent problems with spring freezes at Knoxville and Spring Hill were due to later than normal freeze dates rather than earlier development of the 'Redhaven' peach tree buds. At Springfield, the recent freeze problems were due to earlier breaking of rest, earlier full bloom, and later freezes.
\end{abstract}

A growing concern has emerged about peach crop losses due to late-spring freezes in Tennessee. Years with little or no commercial state production have occurred as recently as 1982, 1983, 1985, 1986, 1987, and 1989. (Tennessee Agricultural Statistics Service, 1987).

To model the rate of peach flower bud development following rest, the date when the peach tree completes its rest period can be estimated (Richardson et al., 1974). Many developmental or phonological models relate the rate of development to the accumulation of temperature above a critical threshold. This accumulation usually is expressed as growing degree days (GDD) or growing degree hours (GDH). The growing degree hour (base $4.4 \mathrm{C}$ air temperature) requirements for critical reproductive stages of 'Redhaven' peach trees have been estimated (Richardson et al., 1975). The GDH requirements are 1981, 2643,2963,3667,4204, 4923, and 5863 for first swelling, green calyx, red calyx, first pink, first bloom, full bloom, and postbloom stages, respectively. GDH are considered to begin accumulation after rest is completed.

For any particular crop, such as peach,

Received for publication 1 Sept. 1989. The cost of publishing this paper was defrayed in part by the payment of page charges. Under postal regulations, this paper therefore must be hereby marked advertisement solely to indicate this fact.

'Assistant Professor.

${ }^{2}$ Associate Professor.

${ }^{3}$ Professor. minimum temperatures have been determined. Below these temperatures, some damage to flower buds is sustained at various stages of floral development. Amount of freeze injury is also influenced by the duration of the freezing temperatures. The average air temperatures that result in $90 \%$ kill of peach buds are $-16.7,-15.0,-12.8$, $-9.4,-6.1,-4.4$, and $-3.9 \mathrm{C}$ for first swelling, green calyx, red calyx, first pink, first bloom, full bloom, and postbloom stages, respectively (Westwood, 1978).

In recent years, serious problems have developed with late-spring freezes and injury to peach tree buds. Examination of the previously published studies of spring freeze dates at given probability levels (Fribourg and Ingram, 1977; National Oceanic and Atmospheric Administration, 1985; Pickett and Bailey, 1964) does not provide sufficient information to assess the spring freeze risks for the peach crop in Tennessee. Whether the severe damage occurs because the spring freezes have been later than normal or because the peach buds have ended rest earlier than normal is unknown. Also, faster bud development after the breaking of rest could result in a more-advanced and freeze-susceptible stage of development when the freeze occurs.

Our objective was to use a simple phenological model involving the chill unit and cultivar Redhaven to study the relationships between peach bud development and spring freezes. The model was evaluated using peach GDH requirements of the common peach orchard data from four locations.

The long-term (1951-89) daily weather records for the Knoxville Plant Science Farm (eastern Tennessee); the Highland Rim Experiment Station, Springfield (middle Tennessee); the Middle Tennessee Experiment Station, Spring Hill (middle Tennessee); and the West Tennessee Experiment Station. Jackson (western Tennessee), were used to estimate daily chill units and GDH. The hourly temperatures were estimated from the daily maximum and minimum temperatures (Richardson et al., 1974). The latitude of the locations ranged from $35^{\circ} 37^{\prime} \mathrm{N}$ to $36^{\circ} 28^{\prime} \mathrm{N}$, the longitude from $83^{\circ} 57^{\prime} \mathrm{W}$ to $88^{\circ} 50^{\prime} \mathrm{W}$ and the respective elevations for the four locations were 252, 226, 213, and $122 \mathrm{~m}$ above sea level.

The estimated daily number of chill units were accumulated from the day after the occurrence of the highest negative accumulation of chill units. The date of completion of rest for 'Redhaven' was estimated as the day when 870 chill units had accumulated after the start of chill unit accumulation (Richardson et al., 1975). Daily GDH were accumulated beginning on the estimated day of rest completion for 'Redhaven' peaches for each year. The daily accumulation of GDH was used to estimate the dates of full bloom and the stage of peach bud development on a day when a frost of $-2.2 \mathrm{C}$ or below occurred. This predictive phonological procedure was repeated for each location and season (September-April), 1951-52 through 198889 (38 years).

Analysis of spring freeze dates indicated that five of the 10 latest spring freezes of $-2.2 \mathrm{C}$ or lower at Knoxville and Spring Hill have occurred since 1980. At Springfield, four of the 10 latest spring freezes of $-2.2 \mathrm{C}$ or lower have occurred since 1980. At Jackson, the freeze-data analysis showed that only two of the 10 latest spring freezes of $-2.2 \mathrm{C}$ or lower have occurred since 1980.

Table 1 shows that the predicted mean fullbloom date at Knoxville (25 Mar.) was 3 days earlier than the actual mean full-bloom date (28 Mar.). At Jackson, the predicted mean full-bloom date (27 Mar. ) was 2 days earlier than the actual mean full-bloom date (29 Mar.). There was no significant difference between predicted and actual mean fullbloom dates at either location.

The average dates and standard errors (in days) for the estimated beginning of chill accumulation, end of rest, and full bloom of 'Redhaven' peaches at the four locations are presented in Table 2 . The average bloom periods (mean full-bloom date \pm 1 week) were 16-30 Mar. at Knoxville, 25 Mar.-8 Apr. at Springfield, 21 Mar.4 Apr. at Spring Hill, and 19 Mar.-3 Apr. at Jackson,

A simulated freeze-damage history for 'Redhaven' peach trees at Knoxville is shown in Table 3. Only those years in which a probable $90 \%$ kill of the peach buds occurred are 
Table 1. Predicted and actual full bloom dates for 'Redhaven' peach buds at Knoxville and Jackson, Tenn.

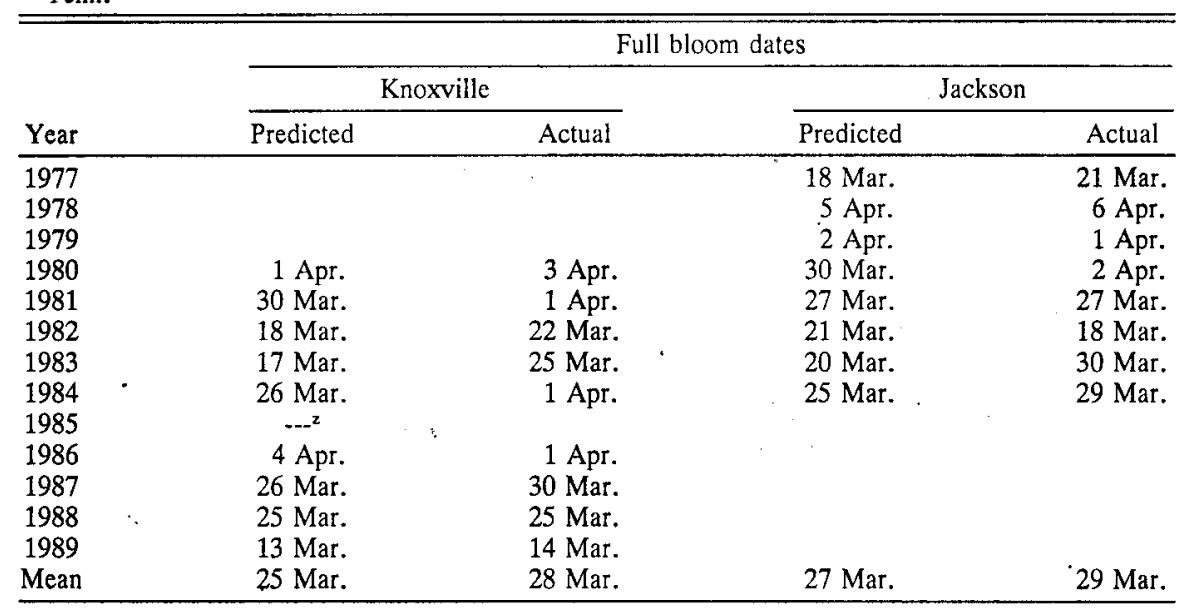

${ }^{2}$ No data available.

Table 2. Average dates of beginning of chill unit accumulation, end of rest, full bloom of 'Redhaven' peach buds, last freeze of $-2.2 \mathrm{C}$ or lower, and the average temperature associated with the last freeze at Knoxville, Springfield, and Jackson, Tenn., 1951-89.

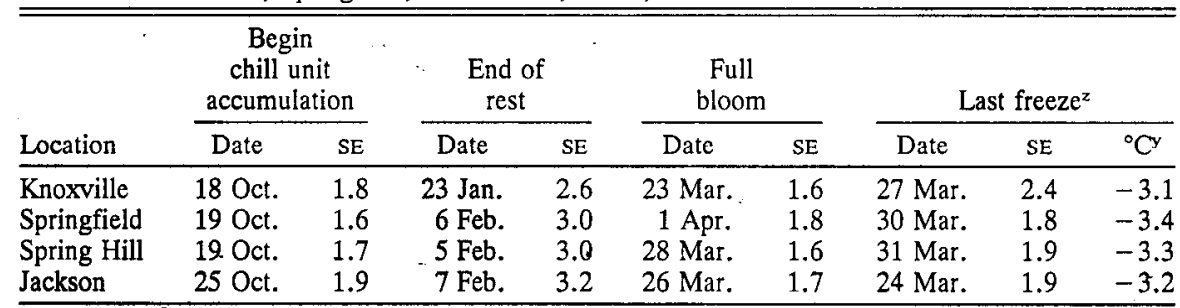

${ }^{2}$ Air temperature of $-2.2 \mathrm{C}$ or lower.

${ }^{y}$ Average temperature $\left({ }^{\circ} \mathrm{C}\right)$ of last freeze.

Table 3. Simulated spring freeze damage ( $\geqslant 90 \%$ kill) history for 'Redhaven' peach buds at Knoxville Experiment Station, Tennessee, 1952-89.

\begin{tabular}{llll}
\hline \hline Year & $\begin{array}{c}\text { Date of } \\
\text { freeze(s) }\end{array}$ & $\begin{array}{l}\text { Minimum } \\
\text { temp }\left({ }^{\circ} \mathrm{C}\right)\end{array}$ & $\begin{array}{l}\text { Estimated stage } \\
\text { of development }\end{array}$ \\
\hline 1954 & 7 Mar. & -6.1 & First bloom \\
& 17 Mar. & -3.9 & Postbloom \\
1955 & 26-28 Mar. & -10.0 to -4.1 & Shuck to fall \\
1956 & 25 Mar. & -3.9 & Postbloom \\
1960 & 15 Feb. & -13.9 & Red calyx \\
& 5-6 Mar. & -14.4 to -11.1 & Red calyx to first pink \\
1965 & 21 Mar. & -7.8 & First bloom to full bloom \\
1967 & 18 Mar. & -6.1 & Postbloom \\
1975 & 3-5 Mar. & -10.0 to -9.4 & First pink \\
& 9 Mar. & -7.2 & First pink to first bloom \\
1977 & $-23 \mathrm{Mar}$. & -5.6 & Full bloom \\
1982 & 27 Mar. & -5.0 & Postbloom \\
& 6 Apr. & -5.6 & Postbloom \\
1983 & 18-19 Apr. & -5.0 to -4.4 & Fruit development \\
1985 & 9-10 Apr. & -5.0 to -3.9 & Postbloom \\
1986 & 23 Apr. & -3.3 & Fruit development \\
1987 & 1 Apr. & -5.0 & Postbloom \\
1989 & 12 Apr. & -3.3 & Fruit development \\
\hline
\end{tabular}

included. A bud mortality of $90 \%$ might still have resulted in a satisfactory yield.

According to the peach orchard data at the Knoxville Experiment Station, at least a partial, spring freeze-out of peach buds occurred six times $(1975,1982,1983,1986$, 1987, and 1989) since 1970. Data from 1985 were not included in the model verification because the buds were frozen while still in rest (20 and 21 Jan. 1985). For the same time period (1970-89), the chill unit/GDH model correctly predicted damaging freezes for the same 6 years. However, freezes of $-2.2 \mathrm{C}$ or lower never occurred during the average bloom period in 1987 or 1989 . The model also correctly predicted the absence of freeze damage in all but one (1977) of the remaining 13 years, even though freezes at or below $-2.2 \mathrm{C}$ occurred during the average bloom period in every year except 1979 .

Since 1952, the model predicted that at least one damaging freeze occurred in 14 out of a possible 38 years $(37 \%)$. This high percentage of damaging freezes represents a significant risk to peach production in the Knoxville area. For the 6 years of predicted freezes since 1980, the average date of the completion of rest was 6 days later than the mean (23 Jan.), the average full-bloom date was 1 day earlier than the mean (23 Mar.), and the average date of the last freeze of $-2.2 \mathrm{C}$ or lower was 19 days later than- the mean (27 Mar.). These results indicate that the recent problems with freeze damage at Knoxville have been due to later than normal freezes.

Some local temperature modification can be a viable option to influence the frequency of freezing temperatures in the spring. An irrigation application rate of $4 \mathrm{~mm} \cdot \mathrm{hr}^{-1}$ combined with a low dewpoint protects blossoms down to $-6.7 \mathrm{C}$ (Childers, 1973). With the minimum temperatures for Knoxville (Table 3), overhead irrigation might have prevented peach bud injury 10 years out of the total 14 freeze years predicted by the model.

At Springfield, (1972-85) freeze-outs occurred four times (1973, 1974, 1978, and 1983). The model predicted damaging freezes in all but one (1978) of these years (data not shown). Freezes of $-2.2 \mathrm{C}$ or lower never occurred during the average bloom period in 1973 and 1978. The model also correctly predicted the absence of freeze damage in all but one (1982) of the remaining 10 years. Four of those years had freezes of $-2.2 \mathrm{C}$ or lower during the average bloom period.

Since 1952, the model predicted that at least one damaging freeze occurred in 11 out of a possible 38 years (29\%). This high percentage of damaging freezes represents a significant risk to peach production in the Springfield area. For the 4 years of predicted freezes since 1980, the average date of the completion of rest was 17 days earlier than the mean $(6 \mathrm{Feb}$.), the average full-bloom date was 6 days earlier than the mean (1 Apr.), and the average date of the last freeze of $-2.2 \mathrm{C}$ or lower was 14 days later than the mean (30 Mar.). These results indicate that the recent problems with freeze damage at Springfield have been due to three factors: earlier breaking of rest, earlier blooming, and later than normal freezes. Frost protection down to $-6.7 \mathrm{C}$ would have proven beneficial in 8 years.

According to 10 years $(1978-85,1988$ 89) of peach orchard data for Spring Hill, at least a partial spring freeze-out of peach buds occurred five times $(1978,1982,1983,1984$, and 1989). Data from 1985 again were not included in the model verification because the buds were frozen while still in rest. The chill unit/GDH model correctly predicted damaging freezes for 4 of these 6 years (data not shown). Freezes of $-2.2 \mathrm{C}$ or lower occurred during the average bloom period in every freeze-out year. The model also correctly predicted the absence of freeze damage in the remaining 4 years, even though freezes of $-2.2 \mathrm{C}$ or lower during the average bloom period occurred three times.

The model for Spring Hill predicted that at least one damaging freeze occurred in 18 out of a possible 37 years (49\%) since 1953, 
representing the highest peach freeze risk in this study. For the 5 years of predicted freezes since 1980, the average date of the completion of rest was 3 days later than the mean (5 Feb.), the average full-bloom date was 4 days earlier than the mean (28 Mar.), and the average date of the last freeze at or below $-2.2 \mathrm{C}$ was 14 days later than the mean (31 Mar.). These results indicate that the recent problems with freeze damage have been due to later than normal freezes. Frost protection down to $-6.7 \mathrm{C}$ would have proven beneficial in 13 years.

Nine years of peach orchard data (197886) for Jackson show only one partial spring freeze-out in 1984, although the buds also were frozen during rest in 1985 . The model indicated no 'crop freeze-out in 1984, as it also did for the 7 years with no recorded freeze-out. There was no freeze at or below $-2.2 \mathrm{C}$ during the average bloom period in 1984. However, there were freezes of $-2.2 \mathrm{C}$ or lower during the average bloom period in 5 of the 7 years with no freeze-out. According to the model, the Jackson area appears to have the least bud-killing freeze risk (4 years out of 38 , or $11 \%$ ) involved with the production of 'Redhaven' peaches.

The use of dates of spring freezes does not allow one to adequately evaluate the risks of peach tree buds at certain stages of bud development. If one assumes that the freeze risk exists only during the average bloom period, then damaging freezes at other stages would be overlooked. In Knoxville, for example, five out of the predicted 14 freezeouts were due to peach bud damage at stages either before or after bloom. Also, the use of the average bloom period (the mean fullbloom date \pm 1 week) maybe too restrictive. In Knoxville, the estimated average bloom period was 16-30 Mar., whereas the range in estimated full-bloom dates (1952-89) was 28 Feb. -5 Apr.

The chill unit/GDH model indicates that the recent problems with spring freeze damage to buds at Knoxville and Spring Hill appear to be due-to later freezes rather than to earlier bud development. At Springfield, recent freeze damage has been due to earlier breaking of rest, earlier full bloom, and later freezes. However, microclimate modification using irrigation may be a viable option at all three locations.

The stage of development of a peach cultivar when a damaging freeze occurs depends on many factors. Among these factors are: date when chill unit accumulation begins; accumulation and negation of chill units over the winter period; prolonged exposure to chilling; and accumulation of GDH after rest is broken. However, a model such as the chill unit/GDH model permits a simple phenological assessment of freeze risks for 'Redhaven' peaches. Knowledge of the manner in which the development of a different cultivar is related to 'Redhaven' could be used to determine the freeze risks for other cultivars.

\section{Literature Cited}

Childers, N.F. 1973. Modern fruit science. 9th ed. Horticultural Publication, Gainesville, Fla. Fribourg, H.A. and D.L. Ingram. 1977. Last spring and first fall freeze dates in Tennessee. Tennessee Farm \& Home Sci. (102):31-35.

National Oceanic and Atmospheric Administration. 1985. Climatography of the United States No. 20, Climatic summaries for selected sites, 1951-80, Tennessee. Nat. Climatic Data Ctr., Asheville, NC.

Pickett, B.S. and M.H. Bailey. 1964. Freeze probabilities in Tennessee. Bul. 374, Univ. of Tennessee Agr. Expt. Sta., Knoxville.
Richardson, E.A., S.D. Seeley, and D.R. Walker 1974. A model for estimating the completion of rest for 'Redhaven' and 'Elberta' peach trees. HortScience 9:331-332.

Richardson, E.A., S.D. Seeley, D.R. Walker, J.L. Anderson, and G.L. Ashcroft. 1975. Pheno-climatology of spring peach bud development. HortScience 10:236-237.

Tennessee Agricultural Statistics Service. 1987. Tennessee Agricultural Statistics. Nashville.

Westwood, M.N. 1978. Temperate-zone pomology. Freeman, New York. 